\title{
Nonlinear trend stationarity of Real Exchange Rates: The case of the Mediterranean countries
}

\author{
Mariam Camarero ${ }^{1}$ \\ Juan Carlos Cuestas ${ }^{2}$ \\ Javier Ordóñez ${ }^{3}$
}

\begin{abstract}
The aim of this article is to provide additional evidence on the fulfilment of the Purchasing Power Parity hypothesis in the so-called Mediterranean countries. In order to test for the empirical validity of such hypothesis, we have applied two types of unit root tests. The first group is due to Bierens (1997) who generalizes the alternative hypothesis to nonlinear trend stationariry and, the second is the Leybourne, Newbold and Vougas (1998) approach that uses a nonlinear specification for the intercept and slope in order to detrend the series. The results suggest that the evidence in favour of the Purchasing Power Parity hypothesis increases when we allow for nonlinear alternatives.
\end{abstract}

J.E.L Classification.: C22, F31

Key words: purchasing power parity, real exchange rate, unit roots, structural change, nonlinearity.

\footnotetext{
${ }^{1}$ Jaume I University, Department of Economics, Campus del Riu Sec, Castellón 12071, Spain; email: camarero@eco.uji.es.

${ }^{2}$ Corresponding author: Nottingham Business School, Division of Economics, Nottingham Trent University, Burton Street, NG1 4BU, Nottingham, UK. e-mail: juan.cuestas@ntu.ac.uk.

${ }^{3}$ Jaume I University, Department of Economics, Campus del Riu Sec, Castellón 12071, Spain; email: jmonfort@eco.uji.es
} 


\section{MARIAM CAMARERO}

Full Professor of International Economics and Jean Monnet Chair in European Economic Integration at the Economics Department, Jaume I University in Castellón (Spain). She holds a $\mathrm{PhD}$ in Economics from the University of Valencia and a Masters Degree in European Economic Integration from the College of Europe (Bruges). She has visited the Wharton School of the University of Pennsylvania (1995-96) and the School of Economics at the University of Nottingham (1992). Her academic publications include articles in the Journal of Comparative Economics, Economics Letters, Oxford Bulletin of Economics and Statistics, The Manchester School, Economic Modeling, Ecological Economics, Weltwirtschasflitches Archiv, Journal of Policy Modeling, and Applied Economics, among others. She coordinates numerous research projects and is the director of a research group on Economic Integration (INTECO).

\section{JUAN CARLOS CUESTAS}

Juan Carlos Cuestas is a Senior Lecturer in Economics at the Nottingham Trent University. He holds $\mathrm{PhD}$ in International and Industrial Economics form the Jaume I University (Spain) and an MSc in Economics and Econometrics from the University of Nottingham. Juan Carlos has visited the School of Economics at the University of Nottingham and the University of Alicante, where

he used to hold a visiting professorship. He has published in journals such as Applied Economics Letters, Applied Financial Economics or The Developing Economies. He is also a member of the INTECO research group.

\section{JAVIER ORDOÑEZ}

Javier Ordoñez is an associate professor of applied economics at the Jaume I University. He holds a $\mathrm{PhD}$ in economics from the same university and an MSc in Economics and Finance from the University of Warwick. He is keen on time series modelling and its applications to exchange rates and unemployment. He has visited the School of Economics at the University of Nottingham and has been assistant research professor at the School of Economics at the University of Copenhagen. He has published in journals such as Economics Letters or Empirical Economics. Javier is also a member of the INTECO research group. 


\section{Introduction}

During the last decades, a number of authors have studied whether Purchasing Power Parity (hereafter PPP), a concept introduced by Cassel in 1918 holds. Since then, the empirical validity of PPP has been tested for different time periods, country-groups and using a variety of econometric techniques. The absolute version of PPP establishes that prices in different countries have to be equal when measured in a common currency, i.e. the nominal exchange rate and the price ratio should share a co-movement along time (cointegrate or share deterministic trends depending on their order of integration). This is equivalent to saying that the real exchange rate, defined as

$$
Q_{t}=\frac{E_{t} P_{t}}{P_{t}^{*}}
$$

is equal to unity, where $Q_{t}$ is the real exchange rate, $E_{t}$ the nominal exchange rate ${ }^{1}$, and $P_{t}^{*}$ and $P_{t}$ are respectively the foreign and domestic price indices. Another less restrictive version is known as relative PPP, and implies that the real exchange rate is a constant different to one. PPP holds when the real exchange rate is stationary so that shocks have only transitory effects.

The empirical analysis of PPP has important implications since it is the base line for many macroeconomic models of real exchange rate determination. Additionally, the PPP values of the currencies can be used as a benchmark to analyze the overvaluation or undervaluation of the currencies, what might influence economic policy decisions. Finally, the PPP can be considered as a measure of economic integration, since the evidence in favour of PPP is stronger for integrated areas (Wei and Parsley, 1995).

The empirical literature on the PPP is very wide. Many different techniques have been used to test for its fulfilment, from Ordinary Least Squares and Instrumental Variables (Frenkel, 1978 and Krugman, 1978) to cointegration (Taylor, 1988, 1992; Johansen and Juselius, 1992; and Doganlar, 1999) and nonlinear techniques (Dixit, 1989; Moosa, 1994; Obstfeld and Taylor, 1997; and Sarno, 2000). Although the empirical literature is vast, the evidence is far from conclusive.

Perron and Phillips (1987) and West (1988), among others, suggest that traditional unit root tests may suffer from lack of power when the deterministic time trend is misspecified. If the variables present structural changes, these tests may conclude that the series analyzed are I(1) when in fact they are stationary around a deterministic time trend or even around a broken time trend (Rappoport and Reichlin, 1989 and Perron, 1989, 1990).

Bearing these considerations in mind some authors have applied unit root tests with structural changes to test for the order of integration of real exchange rates. Following this approach, the results obtained by Dropsy (1996), Parkes and Savvides (1999), and Montañés and Clemente (1999) support PPP.

A broken time trend is a particular case of a nonlinear time trend. Thus, traditional unit root tests, even with structural changes, may incorrectly conclude that the series are I(1) when in fact they are stationary around a nonlinear trend (Bierens, 1997). That means that taking into account one or two structural changes in the deterministic component, does not properly specify the deterministic components. For countries with very unstable economies, where significant sociopolitical events are frequent, with effects on prices and exchange rates, it is sensible to approximate the deterministic components by means of a nonlinear trend, rather than with 
specific structural changes. That the Real Exchange Rate is stationary around a nonlinear deterministic trend implies, therefore, a time varying equilibrium real exchange rate or nonconstant equilibrium exchange rate ${ }^{2}$.

In this paper we study PPP fulfilment for the so-called "Mediterranean countries" (Algeria, Cyprus, Egypt, Israel, Jordan, Malta, Morocco, Syria, Tunisia and Turkey). Unlike other papers, we concentrate on the real exchange rate against the European Union (EU). There are three reasons for the adoption of this approach. First, these countries have agreed with the EU for the creation of a Free Trade Area by 2010, on the basis of the Euroministerial Conference held in Barcelona in 1995. Since the PPP can be considered a measure of economic integration, it may be worthy to test for such relationship between both zones in order to understand their degree of economic integration. Second, former studies such as Sarno (2000), and Camarero, Cuestas and Ordóñez (2006) have highlighted that PPP may not hold for some of these countries. In addition, the latter find that the evidence in favour of PPP increases when the unit root tests allow for structural changes. Additionally, the empirical literature on the empirical analysis of PPP for these countries applying univariate techniques is pretty scarce. Camarero et al. (2006) highlight the fact that the literature in this group of countries, has mainly focused on the analysis of the long run behaviour of the Real Exchange Rate against the US dollar or basket of currencies, without much attention to the relationship against European currencies. The only exception is Laureti (2001) who analyzes PPP against the EU applying a descriptive analysis. Therefore, in the present paper we aim at contributing to the empirical analysis of PPP in the Mediterranean countries, which are becoming increasingly important for the external EU policy decisions.

The aim of this paper is to test whether models allowing for other forms of nonlinear deterministic components are a better statistical characterization of the long-run behaviour of the real exchange rates for this group of countries. In order to do so we apply Bierens (1997) unit root tests that generalize the alternative hypothesis to stationarity around a nonlinear trend. Also, we have applied Leybourne, Newbold and Vougas (1998) unit root test allowing for a smooth transition from one trend function to another. The difference between these two approaches is that Bierens (1997) approximates the nonlinear deterministic trend by Chebishev polynomials, whereas Leybourne et al. (1998) allow for smooth transition not only in the trend but also in the intercept $^{3}$.

To the best of our knowledge, only Assaf (2006) and Cushman (2008) apply Bierens (1997) unit root tests to test for the order of integration of the RER. While the former obtains that the RER is still an integrated process even after accounting for nonlinear deterministic components for a small group of industrialized countries against the US dollar, the latter tests for the order of integration of the RER in group of OECD countries against the US dollar and the Deutch Mark, finding some evidence in favour of the nonlinear trend stationarity hypothesis. Additionally, Sollis (2005) applies the Leybourne et al. (1998) approach to test for PPP for a number of countries against the US dollar finding that this relationship holds for many of them.

The remainder of this paper is organized as follows. In the next section, we summarize Bierens (1997) and Leybourne et al. (1998) unit root tests. In the third section we present the results of such tests applied to PPP in the Mediterranean countries and, finally, the last section summarizes our main results. 


\section{Econometric Methodology}

\subsection{Unit root test with drift versus non-linear trend stationarity}

The common practice in empirical macroeconomics is to model time series as a unit root rather than trend-stationary processes. However, standard unit root tests are not able to reject the I(1) hypothesis in the presence of breaking deterministic linear trends (Perron, 1989, 1990). Thus, time series could be, after all, stationary around a (broken) deterministic linear trend. Bierens (1997) has generalized this idea by suggesting that the macro variable may be stationary around a deterministic nonlinear trend. Such trends are meant to capture the evolution of the underlying data generating processes from changes in the economy's structural parameters (Bierens, 2000).

Park and Choi (1988) and Ouliaris, Park and Phillips (1989) first suggest to use ordinary time polynomials in various standard unit root tests, as the Dickey-Fuller test, to capture the presence of breaking deterministic linear trends. Bierens (1997) revised the nonlinear DickeyFuller version by replacing the ordinary time polynomials with orthogonal Chebishev time polynomials. The advantage of using the Chebishev polynomials is that they allow to distinguish stationarity around a linear trend from stationarity around a nonlinear deterministic trend under the alternative hypothesis.

Denote the Chebishev polynomial as $P_{0, t}$ through $P_{m, t}$, where $P_{0, t}$ equals $1, P_{1, t}$ is equivalent to a linear trend, and $P_{2, t}$ through $P_{m, t}$ are cosine functions. With these polynomials, the augmented Dickey-Fuller test becomes:

$$
\Delta z_{t}=\alpha z_{t-1}+\sum_{j=1}^{p} \phi_{j} \Delta z_{t-j}+\theta^{T} P_{t, n}^{m}+\varepsilon_{t}
$$

Bierens (1997) considers the null of unit root with drift against three alternative hypotheses: stationarity around a level, around a linear trend or around a nonlinear trend. This author develops several test statistics for model (2): $\hat{t}(m)$ which is the t-statistic on the estimated

coefficient $\hat{\alpha}, \hat{A}(m)=\frac{n \hat{\alpha}}{\left|1-\sum_{i=1}^{p} \hat{\phi}_{i}\right|}, \hat{F}(m)$ which is $F$ test for the joint hypothesis that $\hat{\alpha}$ and the last $m$ components of the parameter vector $\theta$ in model (2) are zero under the null. When $H_{0}$ is rejected, the proper alternative hypothesis will depend on the test statistic involved on and whether there is left-side or right-side rejection (see Table 1). Since this test does not follow a standard $F$ distribution, Bierens (1997) provides the distribution fractiles based on Monte Carlo simulation.

In addition, the author develops a model-free unit root test $\tilde{T}(m)$, given that for the $F$ test it is necessary to choose the lag length $p$ in the auxiliary regression and the results may be sensitive to this choice. The model-free unit root test is based on the following regression:

$$
\Delta z_{t}=-\rho z_{t-1}+\lambda_{0}+\rho \lambda_{1} t+f(t)+u_{t}
$$

where $\rho$ lies in the interval $\{0,1\}, f(t)$ is a non-constant deterministic function of time such 
that $\lim _{n \rightarrow \infty}(1 / n) \sum_{t=1}^{n} f(t)=0, \lim _{n \rightarrow \infty}(1 / n) \sum_{t=1}^{n} t f(t)=0$, and $u_{t}$ is a zero-mean process that follows the functional central limit theorem. The null hypothesis of a unit root is formulated as:

$$
H_{0}: \rho=0, f(t) \equiv 0 \text {, }
$$

There are two alternative hypothesis. The first one is linear trend stationarity

$$
H_{1}^{l i n}: \rho=1, f(t) \equiv 0,
$$

whereas the second alternative is nonlinear trend stationarity

$$
H_{1}^{\text {nlin }}: \rho=1 \text {. }
$$

In case of rejection of the null, in order to distinguish between stationarity around a linear or around a nonlinear trend, Bierens (1997) designs the $\tilde{T}(m)$ test. As this test does not have a standard limiting distribution, Bierens (1997) provides the most important fractiles of the distribution for $m=3, \ldots, 20$. Left side rejection would imply linear trend stationarity whereas right side rejection implies nonlinear trend stationarity (as described in Table 1).

Thus, the main advantage of $\tilde{T}(m)$ over $\hat{F}(m)$ is that the former permits the distinction between stationarity around a linear and nonlinear trend. However, in $\tilde{T}(m)$ we assume that the lag length of the auxiliary regression is zero ${ }^{4}$.

\subsection{Smooth transition regression models}

Leybourne et al. (1998) propose a unit root test applied to three logistic smooth transition regression models in an attempt to model structural change as a smooth transition between different regimes rather than as an instantaneous structural break:

$$
\begin{gathered}
y_{t}=\alpha_{1}+\alpha_{2} S_{t}(\gamma, \tau)+v_{t} \\
y_{t}=\alpha_{1}+\beta_{1} t+\alpha_{2} S_{t}(\gamma, \tau)+v_{t} \\
y_{t}=\alpha_{1}+\beta_{1} t+\alpha_{2} S_{t}(\gamma, \tau)+\beta_{2} t S_{t}(\gamma, \tau)+v_{t}
\end{gathered}
$$

where $v_{t}$ is a stationary process with zero mean and $S_{t}(\cdot)$ is the nonlinear function which controls the transition between regimes. The authors define $S_{t}(\cdot)$ as a logistic smooth transition function for a sample size $T$ :

$$
S_{t}(\gamma, \tau)=(1+\exp \{-\gamma[t-\tau T]\})^{-1}, \gamma>0
$$

Model A (equation (7)) approximates the nonlinear deterministic component as a transition in the intercept of a non-trending series, Model B (equation (8)) includes a transition in the intercept of a trending time series and, finally, Model C (equation (9)) uses a transition in the intercept and slope of a trending series (Leybourne et al., 1998).

The above mentioned models can be used to formally test for the order of integration of 
the variables, taking into account the different specification of the deterministic component,

$$
\begin{aligned}
& H_{0}: y_{t}=\mu_{t}, \mu_{t}=\mu_{t-1}+\varepsilon_{t}, \mu_{0}=\psi \\
& H_{1}: \text { Model A, Model B or Model C }
\end{aligned}
$$

and

$$
\begin{aligned}
& H_{0}: y_{t}=\mu_{t}, \mu_{t}=\kappa+\mu_{t-1}+\varepsilon_{t}, \mu_{0}=\psi \\
& H_{1}: \text { Model B or Model C }
\end{aligned}
$$

where $\varepsilon$ is assumed to be an $\mathrm{I}(0)$ process with zero mean $\kappa$ and $\psi$ two constant values.

To apply the unit root tests, Leybourne et al. (1998) propose a procedure that involves two steps. In the first step, the models A, B or C are estimated by Nonlinear Least Squares and the residuals are saved. In the second step, the DF test is applied to the residuals. The null distributions of the tests are approximated using Monte Carlo simulation methods.

\section{Empirical Results}

\subsection{Data}

The data used in the empirical analysis are the log of nominal effective exchange rates $\left(e_{t}\right)$, defined as the price of the national currency in terms of the foreign currency and the log of the price differential relative to the $\mathrm{EU}\left(p_{t}\right)$, computed as national Consumer Price Index minus foreign prices. The log of the real effective exchange rate is then calculated as $e_{t}+p_{t}$. The data have been taken from the International Financial Statistics, IMF. The nominal effective exchange rates and foreign prices have been calculated specifically for each country, using as weights the percentage of trade with their respective EU trade partners. These weights have been obtained from the Direction of Trade Statistics Yearbook, IMF. The frequency of the data is quarterly and spans from 1979:1 to 2002:4. In the case of Tunisia the sample starts in 1987:3.

In figure 1 we display the graphs of the series of the real exchange rates for the Mediterranean countries. The graphical analysis shows that the path of the real exchange rates does not follow, apparently, a linear trend, hence suggesting the possibility of nonlinear deterministic components in the series.

\subsection{Results for the Mediterranean countries real exchange rates}

As a preliminar analysis, first, we display in figure 2 the autocorrelation functions of the RER. The speed of decay of the autocorrelation functions is very slow, implying the presence of a unit root in the series. Additionally, in table 2 we present the results of applying the ADF test to the series of RER. In no case is it possible to reject the unit root hypothesis. This result might be caused by the poor performance of this test when there are nonlinearities in the path of the variable that are not taking into account. 
Now, we analyze the results of the Bierens' (1997) tests. As described above, the $\hat{F}(m)$ test is calculated from the ADF regression where the lag length $p$ has been chosen using the Akaike information criterion (AIC). In addition, we also apply the $\tilde{T}(m)$ test. In this case it is not necessary to choose the lag length, as $p=0$ by definition. Bierens (1997) shows that both tests suffer from important size distortions. Accordingly we have computed the critical values using Monte Carlo simulations based on 10,000 replications of a Gaussian $A R(m)$ process for $\Delta x_{t}$. The parameters and error variances are equal to the estimated $A R(m)$ null model, where the order $p$ of the ADF regression has been selected by the AIC and the initial values are taken from the actual data. In table 3, we present the results of the $\hat{F}(m)$ and $\tilde{T}(m)$ tests. As pointed out by Bierens (1997), there is not a unique way of choosing the value of $m$ : a low value could be not enough to approximate the nonlinear trend, whereas a large value for $m$ might imply low power because of the estimation of redundant parameters. For that reason, table 3 presents the Bierens' test for different orders of $m$.

The results for the $\hat{F}(m)$ test suggest that the null of unit root is rejected for Algeria and Egypt (for large values of $m$ ), as well as for Morocco (in this case for a low length of $m$ ). Although stationarity might be accepted for these three countries, the $\hat{F}(m)$ test does not allow us to distinguish the alternative hypothesis. There are three possibilities: mean stationarity, linear trend stationarity and nonlinear trend stationarity. To complement the analysis, the $\tilde{T}(m)$ test statistic is also computed. The results are similar to those obtained with the $\hat{F}(m)$ test. Thus we do reject the null of unit root for Algeria, Egypt and Morocco, when the alternative is nonlinear trend stationarity (right-sided rejection). Figure 3 displays the graphs of the series in first differences (solid line) for these three countries along with the nonlinear deterministic trends (dotted line) obtained from equation (2.1). From these graphs it is possible to highlight the fact that the Chebishev polynomials appear to be a good approximation for the nonlinear trends.

In table 4 we present the results of the ADF test for the residuals of the STR models ${ }^{5}$. As pointed out by Taylor and Peel (2000), a transition function like (10) implies asymmetric behaviour of the modelled variable, being inappropriate for modelling exchange rate movements. Instead, we use an exponential smooth transition (ESTR) function since the adjustment towards equilibrium is symmetric and does not depend on the sign of the shock. The ESTR function is given by:

$$
S_{t}(\gamma, \tau)=\left(1-\exp \left\{-\gamma^{2}[t-\tau T]^{2}\right\}\right), \gamma>0 \text {. }
$$

The critical values for the DF and ADF tests applied to the residuals of the auxiliar nonlinear regressions are presented in tables 5 and 6, and have been obtained by Monte Carlo simulations over 20,000 replications ${ }^{6}$. The null DGP is been specified as:

$$
y_{t}=\mu_{t}, \mu_{t}=\mu_{t-1}+\varepsilon_{t}, \varepsilon_{t} \sim N I D(0,1) .
$$

According to the results in table 4, we can reject the null of a unit root for the case of Turkey for Model A at the 5\% level of significance, and for Malta for model C at the $10 \%$ level of significance ${ }^{7}$. Nevertheless, as pointed out by Rodrigues and Rubia (2005), the DF test might suffer from power problems in the presence of ARCH effects in the residuals of the DF 
regression. In order to check this point, it has been tested the existence of such effects, finding no evidence of ARCH problems in the residuals ${ }^{8}$.

These results turn out to be complementary to those found by Camarero et al. (2006), as PPP was also fulfilled in the cases of Algeria, Egypt and Turkey, whereas in this case additional evidence is found for Malta when a slow transition is allowed. This joint evidence suggests that the evidence in favour of PPP stationarity improves once the deterministic component is adequately characterized.

\section{Conclusions}

Trying to contribute to the vast literature on PPP, in this paper we have analyzed the empirical fulfilment of PPP in the Mediterranean countries using two unit root tests that take into account the possibility of nonlinearities in the deterministic components.

Our results complement previous evidence on PPP in the Mediterranean countries. First, using Bierens' unit root tests PPP holds for Algeria, Egypt and Morocco, and thus confirm previous results for Algeria and Egypt. On the other hand, by applying Leybourne et al. (1998) approach, there is evidence of PPP fulfillment for Malta and Turkey.

Our conclusion is twofold. First, a proper statistical characterization of the deterministic componentes is of crucial importance when testing for PPP. Second, the use of smooth transition models as a means of representing deterministic structural changes in real exchange rates appears to be appropriate for Malta and Turkey, whereas nonlinear alternatives are adequate for Algeria, Egypt and Morocco.

\section{Acknowledgments}

The authors gratefully acknowledge the financial support from the CICYT and FEDER project SEJ2005-01163, the Bancaja project P1.1B2005-03 and the Generalitat Valenciana Complementary Action ACOMP07/102. The authors are also grateful to two anonymous referees for their helpful comments. The IVIE is also acknowledged. The authors are members of the INTECO research group. The usual disclaimer applies. 


\section{References}

Assaf, A. (2006): "Nonlinear trend stationarity in real exchange rates: Evidence from nonlinear ADF tests", Annals of Economics and Finance, 2, 283-294.

Bierens, H. J. (1997): "Testing the unit root with drift hypothesis against nonlinear trend stationarity, with an application to the U.S. price level and interest rate", Journal of Econometrics, 81, 29-64.

Camarero, M., J. C. Cuestas and J. Ordóñez (2006): "Purchasing power parity versus the EU in the Mediterranean countries”, Applied Financial Economics, 16, 157-167.

Christopoulos, D. and M. A. León-Ledesma (2007): "Post-Bretton-Woods real exchange rates: Mean reverting with breaks and nonlinear adjustment”, mimeo.

Cushman, D. (2008): “Real exchange rates may have nonlinear trends”, International Journal of Finance and Economics, forthcoming.

Dixit, A. (1989): "Hysteresis, import penetration, and exchange rate pass-through", Quarterly Journal of Economics, 104, 205-228.

Doganlar, M. (1999): “Testing long-run validity of purchasing power parity for Asian countries”, Applied Economics Letters, 6, 147-151.

Dropsy, V. (1996): "Real exchange rates and structural breaks”, Applied Economics, 28, 209219.

Frenkel, J. A. (1978): "Purchasing power parity: doctrinal perspective and evidence from de 1920s”, Journal of International Economics, 8, 169-191.

Hegwood, N. D. and D. Papell (1998): "Quasi purchasing power parity”, International Journal of Finance and Economics, 3, 279-289.

Johansen, S. and K. Juselius (1992): "Testing structural hypothesis in a multivariate cointegration analysis of the PPP and the UIP for the UK", Journal of Econometrics, 53, 211244.

Kapetanios, G., Y. Shin and A. Snell (2003): "Testing for a unit root in the nonlinear STAR framework”, Journal of Econometrics, 112, 359-379.

Krugman, P. R. (1978): "Purchasing power parity and exchange rates: Another look at the evidence”, Journal of International Economics, 8, 397-407.

Laureti, L. (2001): "Purchasing power parity and integration: empirical evidence in the mediterranean countries”, Journal of Policy Modelling, 16, 19-35. 
Leybourne, S., P. Newbold and D. Vougas (1998): “Unit roots and smooth transtions”, Journal of Time Series Analysis, 19, 83-97.

MacKinnon, J. G. (1996): "Numerical distribution functions for unit root and cointegration tests”, Journal of Applied Econometrics, 11, 601-618.

Montañés, A. and J. Clemente (1999): "Real exchange rates and structural breaks: Evidence for the Spanish peseta”, Applied Economics Letters, 6, 349-352.

Moosa, I. A. (1994): “Testing nonlinearities in purchasing power parity”, Applied Economics Letters, 1, 41-43.

Obstfeld, M. and M. P. Taylor (1997): "Nonlinear aspects of goods-market arbitrage and adjustment: Hekscher's commodity point revisted", Journal of the Japanese and International Economics, 11, 441-479.

Ouliaris, S., J. Y. Park and P. C. B. Phillips (1989): "Testing for a unit root in the presence of a maintained trend", in Advances in Econometrics and Modelling, edited by B. Raj, Kluwer, 6-28.

Park, J. and B. Choi (1988): “A new approach to testing for a unit root”, CAE Working Paper 88-23, Cornell university.

Parkes, A. L. H. and A. Savvides (1999): "Purchasing power parity in the long run and structural breaks: Evidence from real sterling exchange rates”, Applied Financial Economics, 9, 117-127.

Perron, P. (1989): “The Great Crash, the Oil Price Shock and the unit root hypothesis”, Econometrica, 57, 1361-1401.

Perron, P. (1990): “Testing for a unit root in a time series with a changing mean”, Journal of Business and Economic Statistics, 8, 153-162.

Perron, P. and P. C. B. Phillips (1987): “Does GNP have a unit root? A reevaluation”, Economics Letters, 23, 139-145.

Rappoport, P. and L. Reichlin (1989): "Segmented trends and non-stationary time series", Economic Journal, 99, 168-177.

Rodrigues, P. M. M. and A. Rubia (2005): "The performance of unit root tests under leveldependent heteroskedasticity”, Economics Letters, 89, 262-268.

Sarno, L. (2000): "Real exchange rate behaviour in the Middle East: A reexamination", Economics Letters, 66, 127-136.

Sollis, R. (2005): "Evidence on purchasing power parity from univariate models: the case of smooth transition trend-stationarity”, Journal of Applied Econometrics, 20, no. 1, 79-98. 
Taylor, M. P. (1988): “An empirical examination of long-run purchasing power parity using cointegration techniques”, Applied Economics, 20, 1369-1381.

Taylor, M. P. (1992): "Dollar-Sterling exchange rate in the 1920s: Purchasing power parity and the Norman Conquest of 4.68\$”, Applied Economics, 24, 803-811.

Taylor, M. P. and D. A. Peel (2000): “Nonlinear adjustment, long-run equilibrium and exchange rate fundamentals”, Journal of International Money and Finance, 19, 33-53.

Wei, S.-J. and D. C. Parsley (1995): "Purchasing power disparity during the float rate period: Exchange rate volatility, trade barriers and other culprits”, Working Paper 5032, NBER.

West, K. D. (1988): “Asymptotic normality when regressors have a unit root”, Econometrica, 56, 1397-1418. 
Table 1: Alternative hypotheses

\begin{tabular}{ccc}
\hline Test & $\begin{array}{c}\text { Left-side } \\
\text { rejection }\end{array}$ & $\begin{array}{c}\text { Right-side } \\
\text { rejection }\end{array}$ \\
\hline$\hat{T}(m)$ & LTS & NLTS \\
$\hat{F}(m)$ & - & $\begin{array}{c}\text { MS, LTS or } \\
\text { NLTS }\end{array}$ \\
\hline
\end{tabular}

Note: MS= mean stationarity, LTS= linear trend stationarity, NLTS= nonlinear trend stationarity.

Table 2: ADF test statistics applied to the RER

\begin{tabular}{ccc}
\hline Country & p-value & $k$ \\
\hline Algeria & 0.661 & 0 \\
Cyprus & 0.692 & 0 \\
Egypt & 0.130 & 4 \\
Israel & 0.060 & 2 \\
Jordan & 0.696 & 3 \\
Malta & 0.978 & 0 \\
Morocco & 0.465 & 1 \\
Syria & 0.336 & 0 \\
Tunisia & 0.564 & 0 \\
Turkey & 0.117 & 2 \\
\hline
\end{tabular}

Note: P-values computed by using Mackinnon (1996) critical values. Auxiliary regression for the ADF test with trend and intercept. The order $k$ of the ADF regression has been selected by the AIC. 
Table 3: Bierens (1997) unit root tests

\begin{tabular}{ccccc|cccc}
\hline & \multicolumn{5}{c|}{$\hat{F}(m)$} & \multicolumn{4}{c}{$\tilde{T}(m)$} \\
& $m=5$ & $m=10$ & $m=15$ & $m=20$ & $m=5$ & $m=10$ & $m=15$ & $m=20$ \\
\hline Algeria & 0.74 & 0.04 & 0.80 & 0.98 & 0.92 & 0.30 & 0.94 & 0.94 \\
Cyprus & 0.13 & 0.61 & 0.43 & 0.63 & 0.40 & 0.47 & 0.63 & 0.53 \\
Egypt & 0.80 & 0.84 & 0.99 & 0.99 & 0.94 & 0.95 & 1.00 & 0.99 \\
Israel & 0.03 & 0.23 & 0.09 & 0.55 & 0.09 & 0.31 & 0.65 & 0.87 \\
Jordan & 0.58 & 0.76 & 0.88 & 0.69 & 0.92 & 0.91 & 0.82 & 0.62 \\
Malta & 0.77 & 0.78 & 0.84 & 0.74 & 0.88 & 0.92 & 0.91 & 0.73 \\
Morocco & 0.99 & 0.99 & 0.68 & 0.49 & 0.99 & 0.87 & 0.43 & 0.20 \\
Syria & 0.26 & 0.31 & 0.11 & 0.03 & 0.16 & 0.35 & 0.13 & 0.12 \\
Tunisia & 0.60 & 0.31 & 0.26 & 0.12 & 0.27 & 0.42 & 0.25 & 0.10 \\
Turkey & 0.26 & 0.18 & 0.01 & 0.01 & 0.15 & 0.02 & 0.02 & 0.09 \\
\hline
\end{tabular}

Note: simulated p-values obtained with EasyReg International by Bierens.

Table 4: ADF test statistics applied to the ESTR models

\begin{tabular}{cccc}
\hline Country & $\hat{E}$ & $k$ & Model \\
\hline Algeria & -1.6187 & 0 & $\mathrm{~A}$ \\
Egypt & -2.9185 & 4 & $\mathrm{~A}$ \\
Jordan & -1.7064 & 3 & $\mathrm{C}$ \\
Malta & -4.0187 & 5 & $\mathrm{C}$ \\
Morocco & -3.0117 & 1 & $\mathrm{C}$ \\
Syria & -2.5455 & 0 & $\mathrm{C}$ \\
Tunisia & -2.3816 & 0 & $\mathrm{~A}$ \\
Turkey & -4.7652 & 1 & $\mathrm{~A}$ \\
Note: $\hat{E}$ is the test statistic for the null hypothesis of unit root of the residuals of the ESTR models. The order $k$ of the ADF
\end{tabular}


Table 5: Null critical values for unit root tests against stationarity around a smooth transition: model (A) with smooth drift

\begin{tabular}{|c|c|c|c|c|c|c|}
\hline$n=25$ & $k=0$ & $k=1$ & $k=2$ & $k=3$ & $k=4$ & $k=5$ \\
\hline 0.100 & -4.7516 & -4.4666 & -4.0151 & -3.8256 & -3.4610 & -3.2961 \\
\hline 0.050 & -5.2002 & -4.8794 & -4.3884 & -4.2157 & -3.8127 & -3.6664 \\
\hline 0.010 & -6.1531 & -5.7955 & -5.2508 & -5.0382 & -4.6874 & -4.5617 \\
\hline \multicolumn{7}{|l|}{$n=50$} \\
\hline 0.100 & -4.4654 & -4.3656 & -4.2358 & -4.1932 & -4.0822 & -4.0165 \\
\hline 0.050 & -4.8021 & -4.7295 & -4.5817 & -4.5043 & -4.4053 & -4.3192 \\
\hline 0.010 & -5.5202 & -5.3509 & -5.2338 & -5.0958 & -5.0250 & -4.9604 \\
\hline \multicolumn{7}{|l|}{$n=100$} \\
\hline 0.100 & -4.4288 & -4.3332 & -4.0868 & -3.9851 & -3.8146 & -3.7174 \\
\hline 0.050 & -4.8161 & -4.7106 & -4.4470 & -4.3107 & -4.1285 & -4.0237 \\
\hline 0.010 & -5.6059 & -5.3661 & -5.1243 & -4.9559 & -4.7413 & -4.6694 \\
\hline \multicolumn{7}{|l|}{$n=200$} \\
\hline 0.100 & -4.2374 & -4.2149 & -4.1269 & -4.1038 & -4.0364 & -4.0321 \\
\hline 0.050 & -4.5170 & -4.4946 & -4.4394 & -4.3783 & -4.3157 & -4.3106 \\
\hline 0.010 & -5.1621 & -5.0714 & -5.0571 & -5.0133 & -4.8653 & -4.8865 \\
\hline
\end{tabular}

Note: Nominal sizes $0.10,0.05$ and 0.01 . $\mathrm{k}$ is the order of lags in the ADF regression. 
Table 6: Null critical values for unit root tests against stationarity around a smooth transition: model (C) with smooth drift and trend

\begin{tabular}{|c|c|c|c|c|c|c|}
\hline$n=25$ & $k=0$ & $k=1$ & $k=2$ & $k=3$ & $k=4$ & $k=5$ \\
\hline 0.100 & -4.9454 & -4.6414 & -4.1389 & -3.9724 & -3.5558 & -3.4099 \\
\hline 0.050 & -5.4175 & -5.0999 & -4.5700 & -4.3857 & -3.9443 & -3.8390 \\
\hline 0.010 & -6.3450 & -6.1386 & -5.4386 & -5.2056 & -4.7268 & -4.6855 \\
\hline \multicolumn{7}{|l|}{$n=50$} \\
\hline 0.100 & -4.5961 & -4.4293 & -4.1912 & -4.1282 & -3.9105 & -3.8094 \\
\hline 0.050 & -4.9863 & -4.7932 & -4.5634 & -4.4731 & -4.2652 & -4.1707 \\
\hline 0.010 & -5.7703 & -5.5672 & -5.2794 & -5.2029 & -5.0229 & -4.8374 \\
\hline \multicolumn{7}{|l|}{$n=100$} \\
\hline 0.100 & -4.2889 & -4.2300 & -4.1070 & -4.0616 & -3.9456 & -3.9092 \\
\hline 0.050 & -4.6072 & -4.5481 & -4.4011 & -4.3689 & -4.2569 & -4.2054 \\
\hline 0.010 & -5.2206 & -5.1407 & -5.0321 & -4.9010 & -4.8075 & -4.7791 \\
\hline \multicolumn{7}{|l|}{$n=200$} \\
\hline 0.100 & -4.0305 & -3.9845 & -3.9234 & -3.8907 & -3.8265 & -3.8167 \\
\hline 0.050 & -4.3371 & -4.2920 & -4.2239 & -4.1990 & -4.1363 & -4.1112 \\
\hline 0.010 & -4.9329 & -4.8852 & -4.8285 & -4.8269 & -4.7551 & -4.7004 \\
\hline
\end{tabular}


Figure 1: Real Exchange Rates

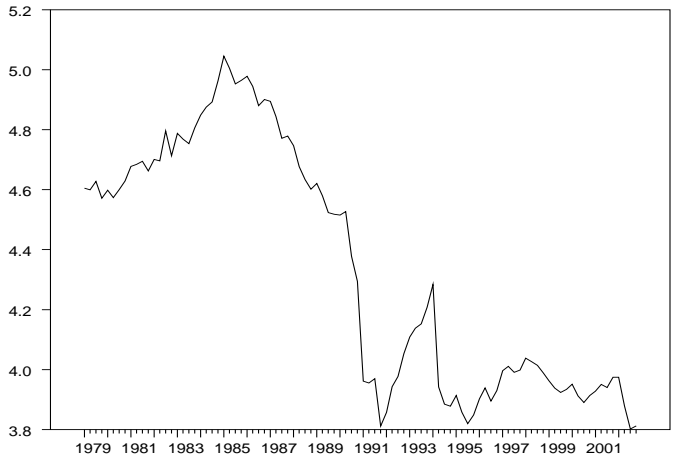

Algeria

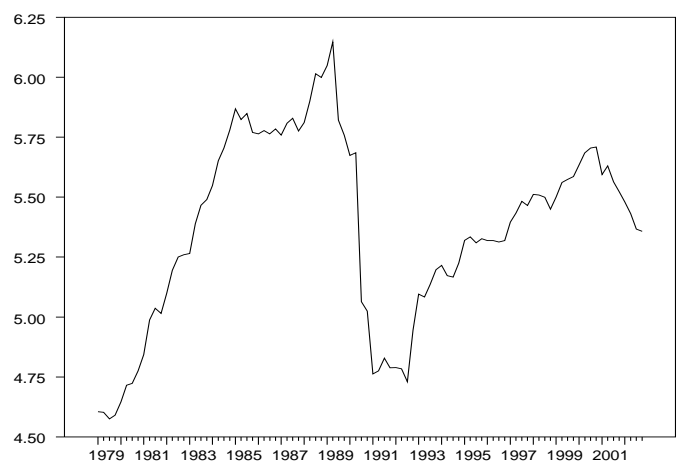

Egypt

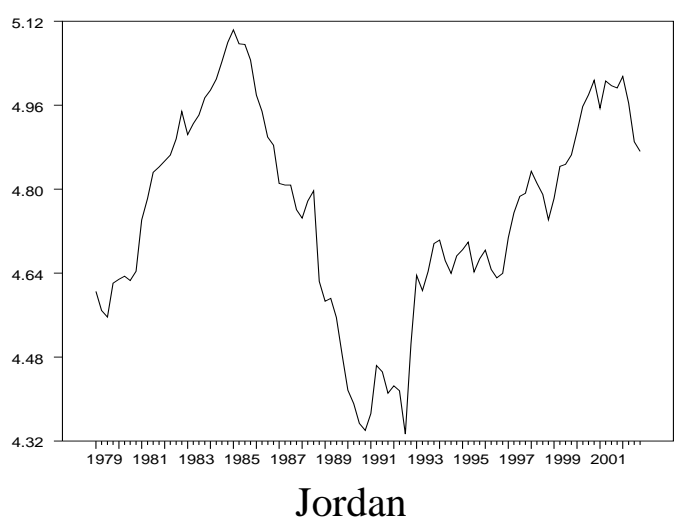

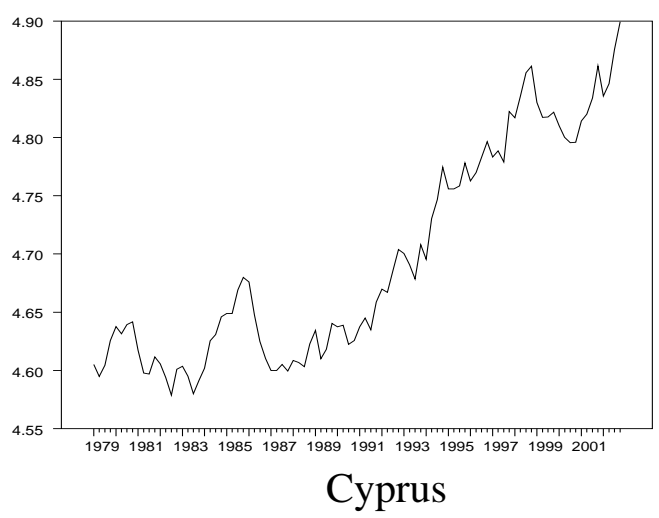
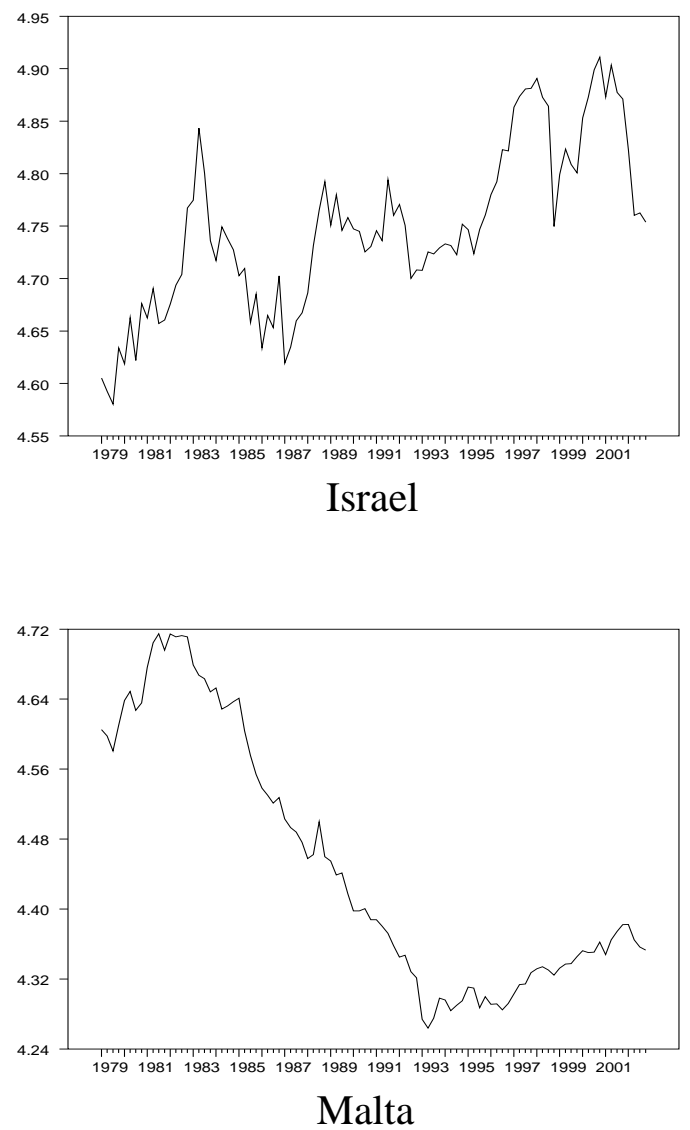

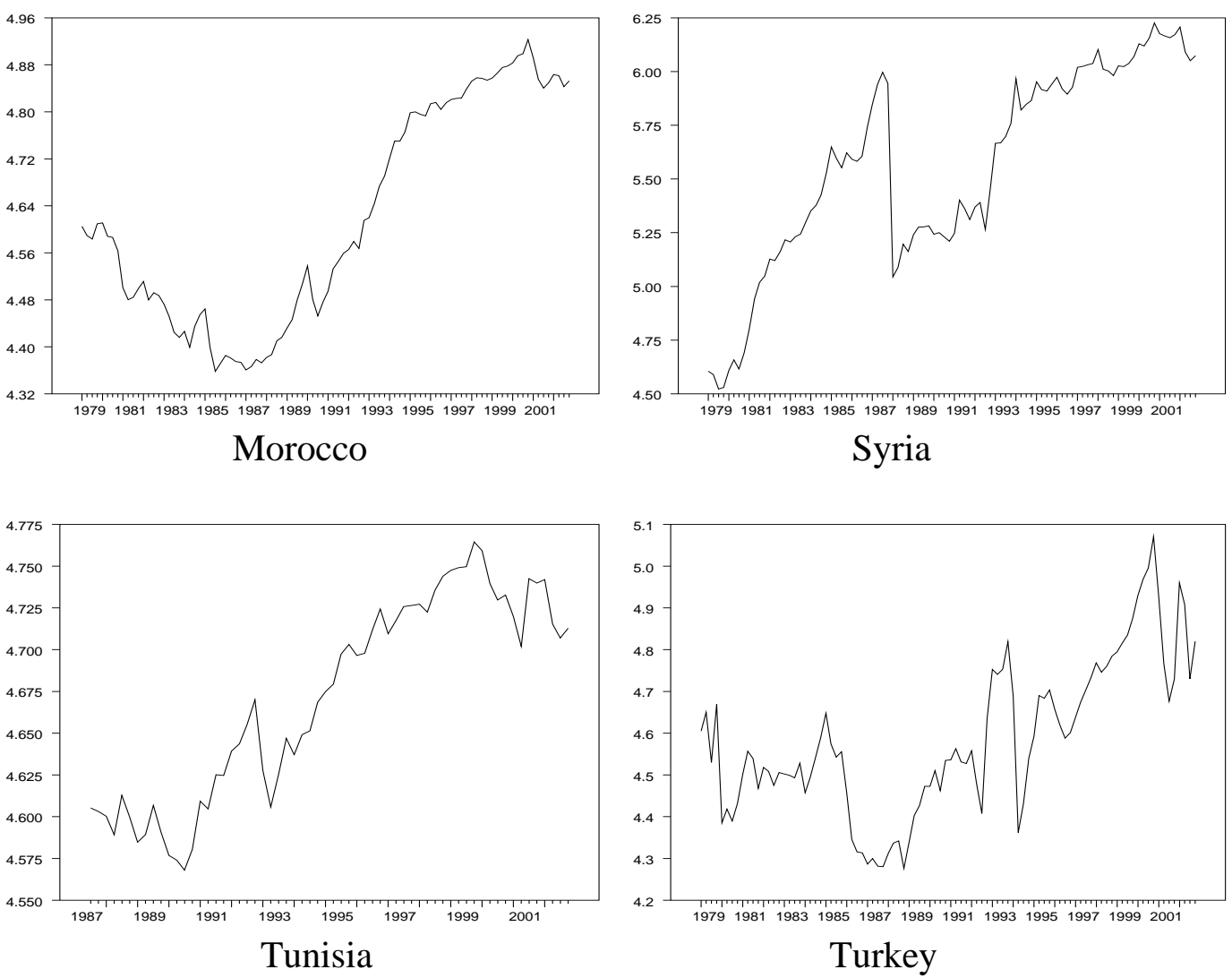
Figure 2: Autocorrelation functions
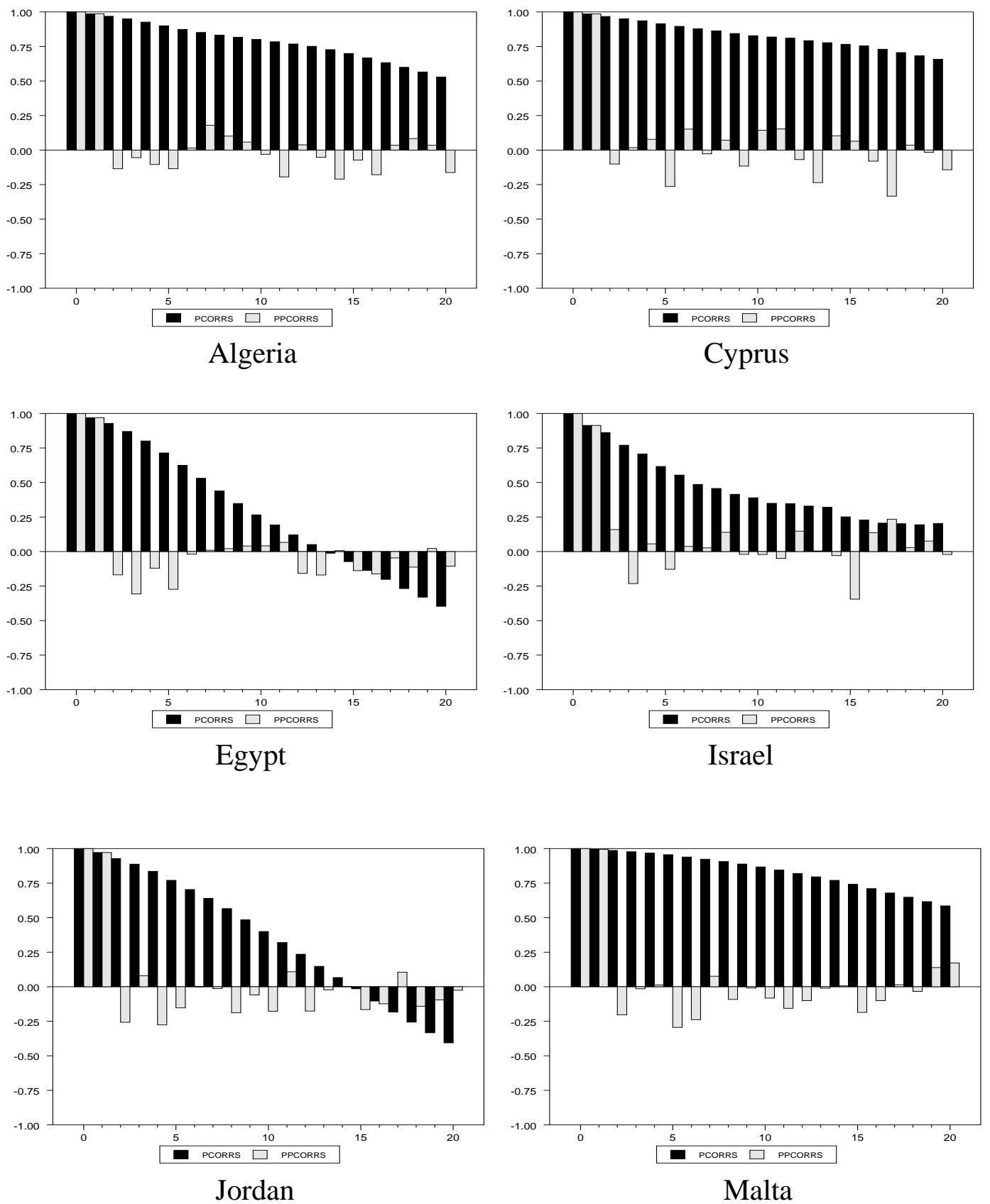

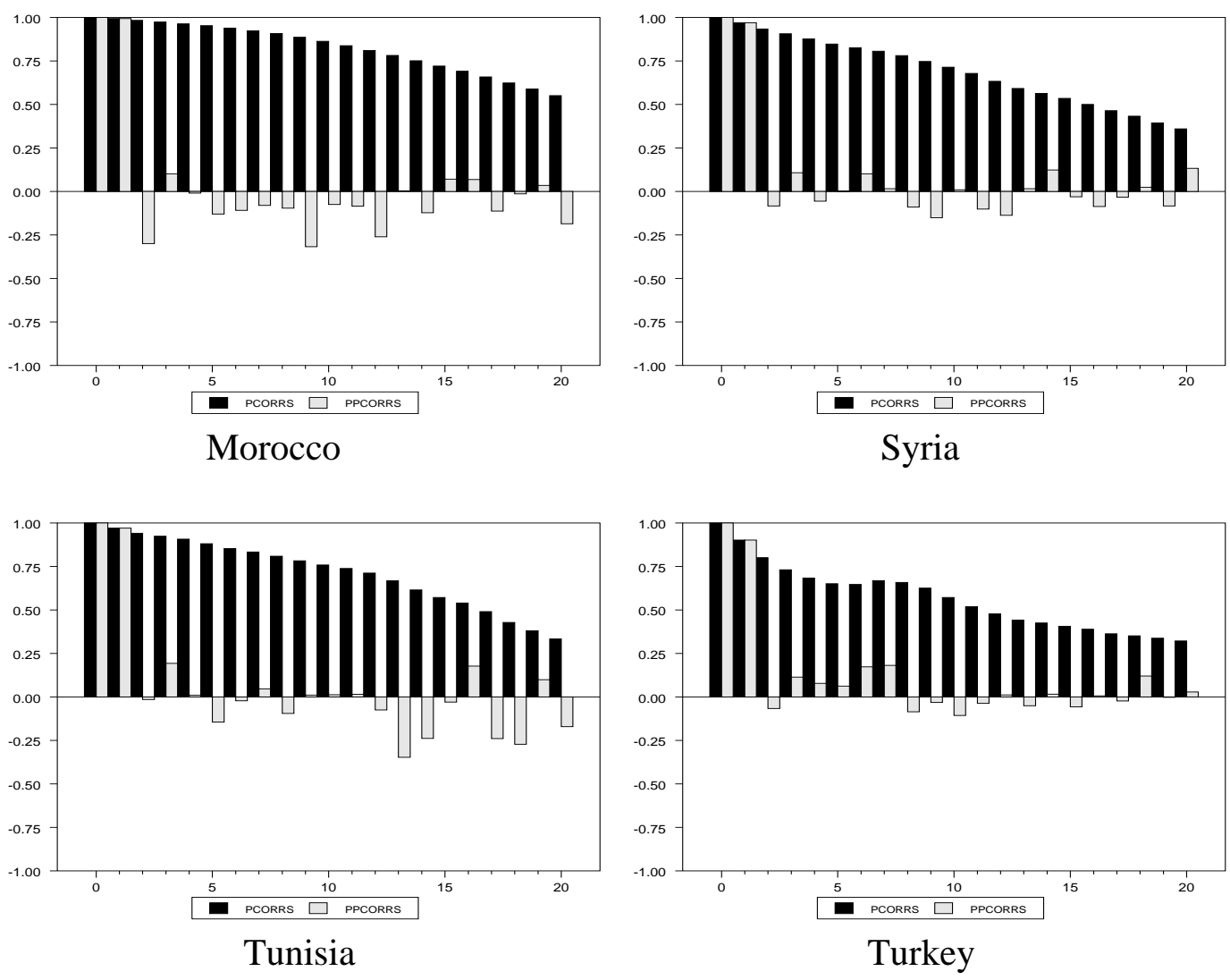


\section{Figure 3: Nonlinear trends (Chebishev polynomials)}
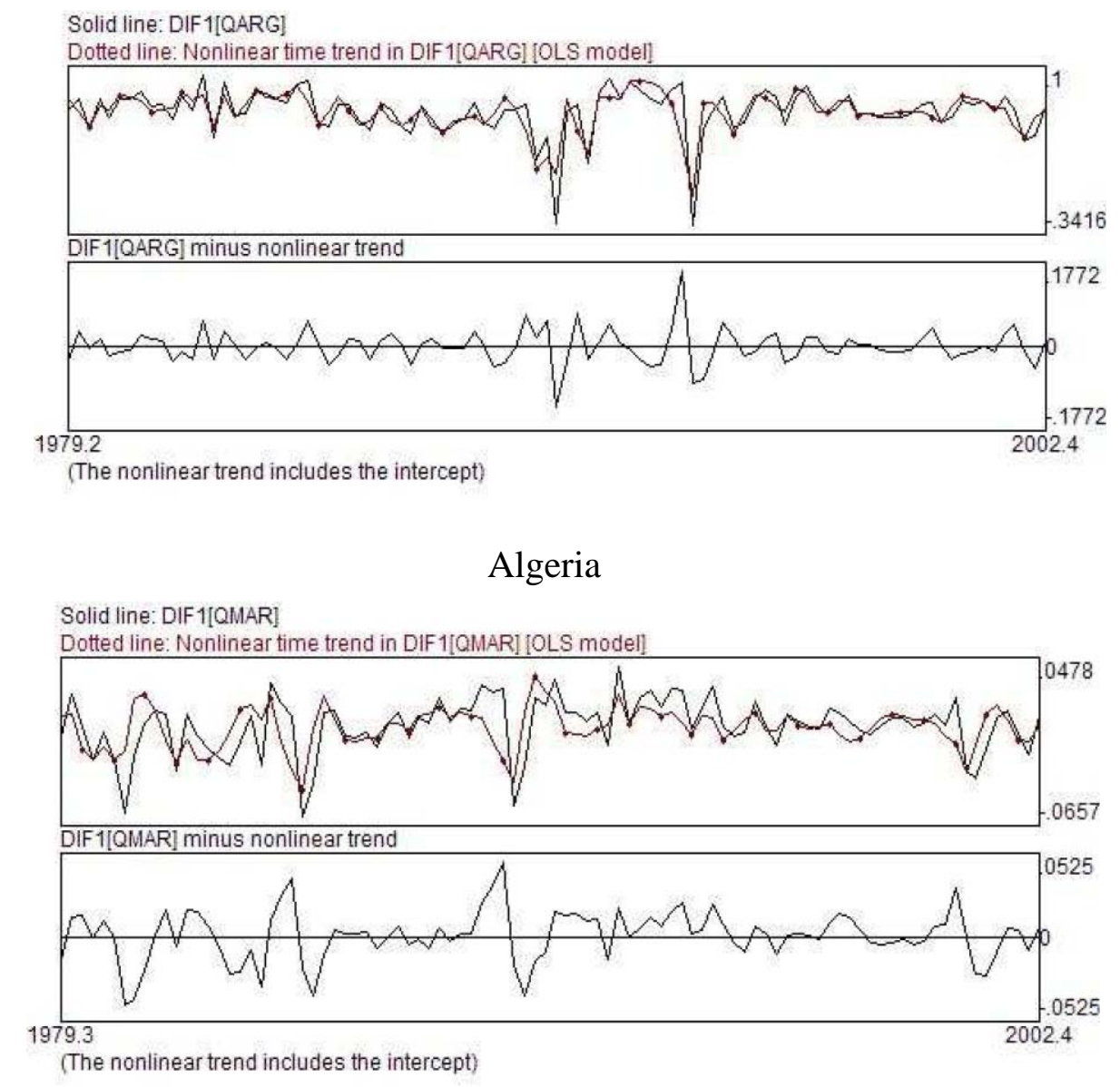

Egypt

Solid line: DIF1[QEG]

Dotted line: Nonlinear time trend in DIF1[QEGI] [OLS model]
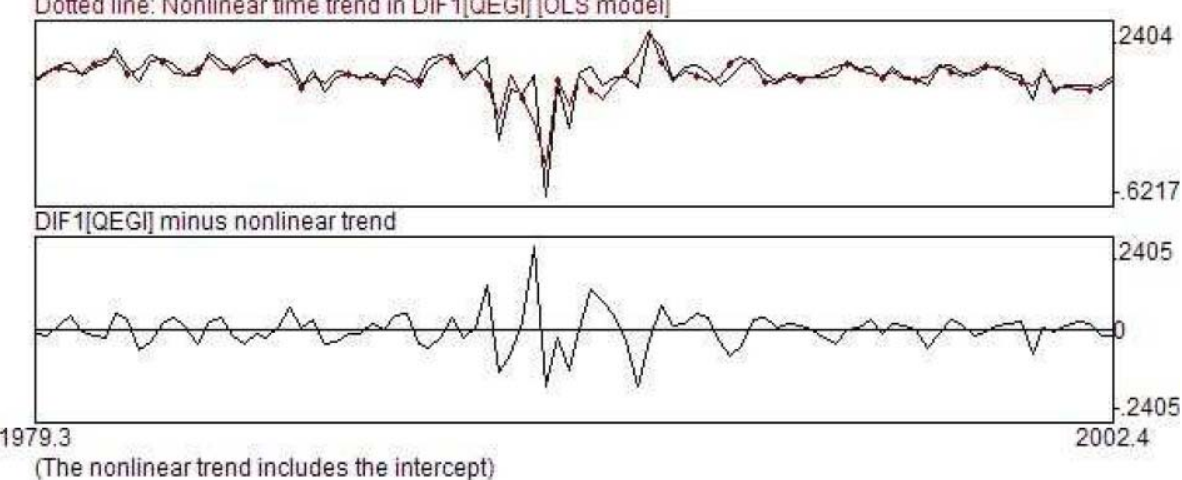

Morocco 


\section{Notes}

${ }^{1}$ Units of foreign currency for a unit of domestic currency.

${ }^{2}$ Hegwood and Papell (1998) called it Quasi-PPP.

${ }^{3}$ See Michael, Nobay and Peel (1997) for the adequacy of smooth transition models vs. threshold models to characterize the long-run behaviour of real exchange rate.

${ }^{4}$ The ADF-type regression becomes a DF-type regression.

${ }^{5}$ The results for Cyprus and Israel does not provide evidence for the existence smooth transitions either in the intercept or in the slope.

${ }^{6}$ The Nonlinear Least Squares estimation was computed using the optimization algorithm in the OPTMUM subroutine library of GAUSS. The initial values were obtained using the SIMPLEX algorithm.

${ }^{7}$ As pointed out by one referee, the fact that we fail to find evidence in favour of the PPP hypothesis for some countries with both tests might be due to the fact that we are dealing with short samples (96 observations for all the countries, except for Tunisia where the sample only spans 62 observations), and these tests might still suffer from power problems when applied to short samples. In addition, we have to bear in mind that additional sources of nonlinearities are not being taken into account with these unit root tests, i.e. asymmetric adjustment, that might affect the performance of the tests (see Kapetanios, Shin and Snell, 2003, and Christopoulos and León-Ledesma, 2007, among others).

${ }^{8}$ Results available upon request to the authors. 